\title{
Adenovirus encoding soluble tumor necrosis factor $\alpha$ receptor immunoglobulin prolongs gene expression of a cotransfected reporter gene in rat lung
}

Takashi Suda, MDa

Tsutomu Tagawa, MD ${ }^{a}$

Samer A. Kanaan, MD ${ }^{\mathrm{a}}$

Benjamin D. Kozower, MDa

Niccolò Daddi, MD

T. Mohanakumar, $\mathrm{PhD}^{\mathrm{b}}$

G. Alexander Patterson, MD, FRCS(C) ${ }^{\mathrm{a}}$

See related article on page 1147.
From the Division of Cardiothoracic Surgery $^{\mathrm{a}}$ and the Department of Surgery, ${ }^{\mathrm{b}}$ Washington University School of Medicine, Barnes Jewish Hospital, St Louis, Mo.

Supported by the National Institutes of Health grants RO1 HL-41281 (Dr Patterson) and R01 HL56643 (Dr Mohanakumar). Dr Kanaan is supported by individual NRSA-NIH grant 1F32HL68401-01.

Received for publication Oct 25, 2002; revisions requested Dec 27, 2002; revisions received May 20, 2003; accepted for publication June 3, 2003.

Address for reprints: G. Alexander Patterson, MD, Division of Cardiothoracic Surgery, Washington University School of Medicine, One Barnes-Jewish Hospital Plaza, 3108 Queeny Tower, St. Louis, MO 63110 (E-mail: pattersona@msnotes.wustl. edu).

J Thorac Cardiovasc Surg 2003;126: $1155-61$

Copyright ( 92003 by The American Association for Thoracic Surgery

$0022-5223 / 2003 \$ 30.00+0$

doi:10.1016/S0022-5223(03)00939-5
Objective: Because almost all pulmonary diseases are not caused by one gene, multiple gene transfection is required for current gene therapy. Adenovirus is an important gene therapy vector, but a short duration and the inability of repeated administration remain limitations. The aims of this study were to evaluate whether adenoviral vector encoding soluble tumor necrosis factor $\alpha$ receptor immunoglobulin and $\beta$-galactosidase cotransfection prolongs gene expression and facilitates repeated vector administration to investigate the feasibility of a cotransfection strategy.

Methods: F344 rats received intratracheal administration of $1 \times 10^{9}$ plaque-forming units of adenoviral vector encoding $\beta$-galactosidase or both adenoviral vector encoding $\beta$-galactosidase and adenoviral vector encoding soluble tumor necrosis factor $\alpha$ receptor immunoglobulin. In the expression study $\beta$-galactosidase gene expression in the lung was examined by means of enzyme-linked immunosorbent assay on days $2,7,14,28$, and $56(\mathrm{n}=4 /$ day). In the repeated transfection study, soluble tumor necrosis factor $\alpha$ receptor immunoglobulin and $\beta$-galactosidase were readministered once ( 7 days after the first adenovirus administration) or twice (on days 7 and 14; $n=4 /$ day). A 2-way factorial analysis of variance was used for statistical analysis.

Results: Soluble tumor necrosis factor $\alpha$ receptor immunoglobulin and $\beta$-galactosidase cotransfection prolonged the duration of $\beta$-galactosidase expression. However, antiadenovirus antibody production was significantly increased in the cotransfection group. In addition, there was no increase in $\beta$-galactosidase expression after readministration of soluble tumor necrosis factor $\alpha$ receptor immunoglobulin and $\beta$-galactosidase.

Conclusion: Adenoviral vector encoding soluble tumor necrosis factor $\alpha$ receptor immunoglobulin and $\beta$-galactosidase cotransfection prolongs $\beta$-galactosidase expression but does not increase $\beta$-galactosidase expression after repeated administration. These results suggest that tumor necrosis factor $\alpha$ is one of the most important factors in regulating the duration of gene expression. The cotransfection approach is feasible, but the increase of antiadenovirus antibodies might make repeated cotransfection unfeasible.

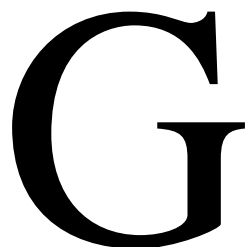
ene therapy with recombinant adenoviral vectors is currently being used in many clinical gene transfer trials for lung diseases, such as cystic fibrosis and lung cancer. ${ }^{1-3}$ In experimental lung transplantation our laboratory has demonstrated the beneficial effects of gene transfer on ischemia-reperfusion injury and acute rejection in a rat lung graft model by using adenovirus vectors, cationic lipid vectors, and naked plasmid. ${ }^{4-6}$ 
Recombinant adenoviral vectors have an excellent safety record and lend themselves readily to commercial-scale manufacturing. They have been used as the gene-transfer vector in most clinical studies to date and are efficient vehicles for gene delivery to nondividing epithelial cells in the airway. Adenoviruses can be produced and purified in very high titer, permitting highly efficient gene transfer in a single administration. However, the duration of expression is limited by the ability of the gene to replicate during cell division. There is also evidence that the first-generation adenoviral vectors induce a cellular immune response in the recipient, leading to selective destruction of infected cells and subsequent loss of expression within 14 to 21 days of transfection. In addition, the in vivo administration of adenovirus vectors frequently elicits a neutralizing antibody response, which reduces the efficacy of subsequent treatments. Methods such as immunosuppression will be required to overcome this barrier and enable repeat delivery of adenovirus-based gene therapy for the treatment of chronic disease. ${ }^{7,8}$ Use of second-generation adenoviruses (deletion of E1 and E4 regions) and standard immunosuppression decrease the inflammatory reaction caused by the adenovirus. ${ }^{9}$ Cassivi and colleagues ${ }^{10,11}$ demonstrated that immunosuppression attenuates the host immune response after adenovirus-mediated transfection of rodent lungs and that transgene expression after adenovirus-mediated retransfection is increased and prolonged by transplant immunosuppression.

Tumor necrosis factor $\alpha$ (TNF- $\alpha$ ) is the principal mediator of the acute inflammatory response to many infectious microbes and is responsible for many of the systemic complications of severe infections and other inflammatory conditions. For example, in experimental arthritis models and patients with rheumatoid arthritis, neutralization of TNF- $\alpha$ with a soluble type I TNF- $\alpha$ receptor immunoglobulin (Ig) $\mathrm{G}$ fusion protein alone ${ }^{12,13}$ or with an adenoviral vector construct $^{14-16}$ decreases arthritic inflammation. Ghivizzani and associates ${ }^{16}$ used the TNF- $\alpha$ receptor IgG fusion protein rather than the soluble TNF receptor alone because frequent administration was required, and the effect was short lived with just the receptor. The effectiveness of TNF- $\alpha$ antagonists, such as soluble tumor necrosis factor $\alpha$ receptor immunoglobulin (sTNF-RI-Ig), in ameliorating inflammation of the liver and lung has also been demonstrated by Zhang and coworkers. ${ }^{17}$ On the basis of these studies, we chose to use sTNF-RI-Ig in our current study.

Almost all disease processes involve not only 1 but 2 or more genes, and this can become an important problem for the future use of gene therapy, which currently transfects only one gene. Multiple-gene transfer, such as cotransfection, might permit modulation of concurrent biochemical pathways involved in lung diseases. Our laboratory has shown a synergistic benefit by using interleukin 10 and transforming growth factor $\beta 1$ compared with transfection of either cytokine alone. ${ }^{18}$ However, this approach might increase the quantity of adenovirus transfected and augment the formation of antibodies to the adenovirus vector. Unfortunately, the antiadenovirus antibodies might reduce the degree and duration of transgene expression. Importantly, TNF- $\alpha$ has a crucial role in immune-mediated clearance of adenoviral vectors, and adenovirus gene therapy is prolonged in TNF- $\alpha$ knockout mice. ${ }^{19}$ Therefore, we hypothesized that use of a cotransfection approach with the adenoviral vector encoding soluble type I TNF- $\alpha$ receptor IgG fusion protein might prolong gene expression and permit repeated transfection.

The aims of this study were to investigate the feasibility of the cotransfection strategy by (1) evaluating the effect of sTNF-RI-Ig and $\beta$-galactosidase ( $\beta$-gal) gene cotransfection on achieving prolonged $\beta$-gal expression and (2) examining the effects of sTNF-RI-Ig and $\beta$-gal gene cotransfection on $\beta$-gal gene expression after their repeated administration. The present study demonstrated that sTNF-RI-Ig and $\beta$-gal cotransfection was feasible and prolonged the duration of $\beta$-gal gene expression. However, repeated administration of sTNF-RI-Ig and $\beta$-gal did not have any effect on increasing $\beta$-gal expression. Therefore, we also examined the production of endogenous TNF- $\alpha$ in transfected lungs and antiadenovirus antibodies to investigate the mechanisms of prolonging gene expression.

\section{Materials and Methods Animals}

F344 rats (Harlan Sprague Dawley Inc, Indianapolis, Ind) weighing 250 to $270 \mathrm{~g}$ were used in all experiments. All animal procedures were approved by the Animal Studies Committee at Washington University. Animals received humane care in compliance with the "Guide for the Care and Use of Laboratory Animals" prepared by the National Academy of Sciences and published by the National Institutes of Health (National Institutes of Health publication No. 85-23, revised 1985).

\section{Adenoviral Vectors}

The recombinant adenovirus serotype 5 carrying the Escherichia coli LacZ gene encoding for $\beta$-gal is driven by the constitutive cytomegalovirus promoter (Gene Therapy Center, University of North Carolina, Chapel Hill, NC).

Adenovirus TNF- $\alpha$ receptor Ig (AdsTNF-RI-Ig) encodes a fusion protein consisting of the extracellular domain of the human 55-kd TNF- $\alpha$ receptor and the $\mathrm{Ch} 2$ through $\mathrm{Ch} 3$ domains of a mouse IgG1 heavy chain. ${ }^{11}$ AdsTNF-RI-Ig was a gift from Dr Paul D. Robbins (Department of Molecular Genetics and Biochemistry, University of Pittsburgh, Pittsburgh, Pa). Purified viral aliquots were stored at $-80^{\circ} \mathrm{C}$ in $10 \%$ glycerol buffered with $10 \mathrm{mmol} / \mathrm{L}$ Tris, $140 \mathrm{mmol} / \mathrm{L} \mathrm{NaCl}$, and $1 \mathrm{mmol} / \mathrm{L} \mathrm{MgCl}_{2}$. Immediately before use, these stocks were thawed and diluted in $0.6 \mathrm{~mL}$ of sterile normal saline. 


\section{Experimental Groups}

Animals were transfected intratracheally with $1 \times 10^{9}$ plaqueforming units (pfu) of adenovirus encoding AdCMVlacZ* alone ( $\beta$-gal group) or $1 \times 10^{9}$ pfu of both AdCMVlacZ and AdsTNFRI-Ig (cotransfection group).

Experiment 1: Demonstrate in vivo gene delivery and confirm expression in the lung of the cotransfected genes sTNF-RI-Ig and $\boldsymbol{\beta}$-gal. Two days after cotransfection, sTNF-RI-Ig and $\beta$-gal gene expression in the lung was evaluated by means of immunohistochemistry.

Experiment 2: Evaluate the effect of sTNF-RI-Ig and $\beta$-gal gene cotransfection on achieving prolonged $\beta$-gal expression. The $\beta$-gal gene expression in the lung was examined by means of enzyme-linked immunosorbent assay (ELISA) on days 2, 7, 14, 28 , and 56 after cotransfection of sTNF-RI-Ig and $\beta$-gal $(\mathrm{n}=$ $4 /$ day). Antiadenovirus antibodies in the serum were measured by means of ELISA on each day as well.

Experiment 3: Examine the effects of sTNF-RI-Ig and $\beta$-gal gene cotransfection on $\beta$-gal gene expression after their repeated administration. STNF-RI-Ig and $\beta$-gal were readministered once (7 days after the first adenovirus transfection) or twice (on days 7 and 14). Initial $\beta$-gal gene expression in the lung was compared with the expression on day 7 , before the retransfection, and on days 9,14 , and 16 , before the second retransfection, by means of ELISA ( $n=4$ each). $\beta$-Gal protein expression after readministration was measured to determine whether repeated gene transfection was successful.

\section{Immunohistochemistry of $\beta$-gal and sTNF-RI}

Tyramide Signal Amplification Biotin System kits (NEN Life Science Products, Inc, Boston, Mass) were used for immunohistochemistry. Briefly, lungs were perfused with $20 \mathrm{~mL}$ of normal saline and $20 \mathrm{~mL}$ of HistoChoice (Amresco, Solon, Ohio). Specimens were fixed, cut, mounted, deparaffinized, and then treated with Dako Target Retrieval Solution (Dako, Carpinteria, Calif). Sections were incubated for 60 minutes with an Fc $\gamma$ II receptor blocker (BD PharMingen, San Diego, Calif) and with Super Block Blocking Buffer (Pierce Chemical Company, Rockford, Ill). A biotinylated anti-hTNF RI antibody (R\&D Systems, Minneapolis, Minn) was used for 1 hour at room temperature at 1:40 dilution without amplification, washed in PBS, and then incubated with streptavidin-horseradish peroxidase for 30 minutes. Next we detected with DAB substrate (Vector Labs, Burlingame, Calif). This produced a brown color. Then sections were blocked again for 30 minutes with Super Block as before and incubated with B-Gal (Polysciences, Warrington, Pa) at 1:500 overnight at $4{ }^{\circ} \mathrm{C}$. The next day, sections were incubated with a biotin anti-rabbit IgG Readyto-Use (BioGenex, San Ramon, Calif) for 30 minutes and amplified with the Tyramide Signal Amplification kit. Sections were incubated with streptavidin-horseradish peroxidase for 30 minutes and then 15 minutes with biotinyl tyramide, followed by 30 minutes with streptavidin-alkaline phosphatase. We detected the BGal with NBT/BCIP (Vector Labs) for the bluish-purple color. Slides were then counterstained with methyl green, dehydrated, mounted, and cover slipped. For negative controls, we used normal

*Escherichia coli lacZ gene, which encodes $\beta$-galactosidase, driven by the constitutive cytomegalovirus promoter. lung with both antibodies. We also tested each antibody on a lung sample with single transfection.

\section{ELISA}

Blood samples $(3 \mathrm{~mL})$ were collected into ethylenediamine tetraacetic acid-containing tubes with pepstatin $\mathrm{A}(5 \mu \mathrm{g} / \mathrm{mL})$ and protease inhibitor cocktail (Complete Mini tabs; BoehringerMannheim, Mannheim, Germany). Plasma was obtained by means of centrifugation at $1000 \mathrm{~g}$ for 30 minutes, centrifuged at $15,000 \mathrm{~g}$ for 15 minutes, and stored at $-80^{\circ} \mathrm{C}$ until ELISA assessment. Lung protein was extracted by means of homogenization in lysis solution containing $100 \mathrm{mmol} / \mathrm{L}$ potassium phosphate $(\mathrm{pH} \mathrm{7.8),}$ $0.2 \%$ triton $\mathrm{X}-100$ with pepstatin A $(5 \mu \mathrm{g} / \mathrm{mL})$, and protease inhibitor cocktail (Complete Mini tabs, Boehringer-Mannheim). The homogenate was centrifuged at $15,000 \mathrm{~g}$ for 15 minutes after extraction at room temperature for 15 minutes, and the supernatant was stored at $-80^{\circ} \mathrm{C}$ until ELISA assessment. The human sTNF-RI and rat TNF- $\alpha$ ELISA kits (R\&D Systems) and the $\beta$-gal ELISA kit (Boehringer-Mannheim) were used for protein quantification. The human sTNF-RI is cross-reactive for human, rat, and mouse.

\section{ELISA for Antiadenovirus Antibody Production}

Viable AdCMVlacZ ( $\left.10^{9} \mathrm{pfu}\right)$ was added to lung homogenate and incubated overnight at $4^{\circ} \mathrm{C}$, and the plates were washed 3 times. Serum samples were diluted 1:1000, incubated for 2 hours at room temperature, and washed. A goat anti-rat $\mathrm{IgG}$ was added, and the plates were washed again and developed with ABTS Substrate Solution, which contains ABTS (150 mg; 2,2-azino-bis-[3-ethylbenzthiazoline-6-sulfonic acid]) and $0.1 \mathrm{~mol} / \mathrm{L}$ anhydrous citric acid. The optical density was determined at $405 \mathrm{~nm}$ on a microplate reader. Each sample was assayed in duplicate, and the optical density reading for each sample was averaged. The neutralizing antibody assay procedure was similar to that reported by Gall and colleagues. $^{20}$

\section{Statistical Analysis}

Values are reported as means \pm SEM. A 2-way factorial analysis of variance was used for statistical analysis when 2 different groups of samples were compared.

\section{Results}

Experiment 1: Demonstrate in vivo gene delivery and confirm expression in the lung of the cotransfected genes STNF-RI-Ig and $\beta$-gal

Positive immunohistochemical double staining for sTNFRI-Ig and $\beta$-gal was observed in airway epithelial cells of cotransfected lungs (Figure 1). Lungs transfected with $\beta$-gal alone showed only positive staining for $\beta$-gal and not sTNFRI-Ig, whereas lungs flushed with saline alone did not stain positive for either gene.

Experiment 2: Evaluate the effect of sTNF-RI-Ig and $\beta$-gal gene cotransfection on achieving prolonged $\beta$-gal expression

Mean sTNF-RI-Ig protein expression in the cotransfection group was detected on day $2(44.7 \pm 12.0 \mathrm{ng} / \mathrm{mg}$ total 

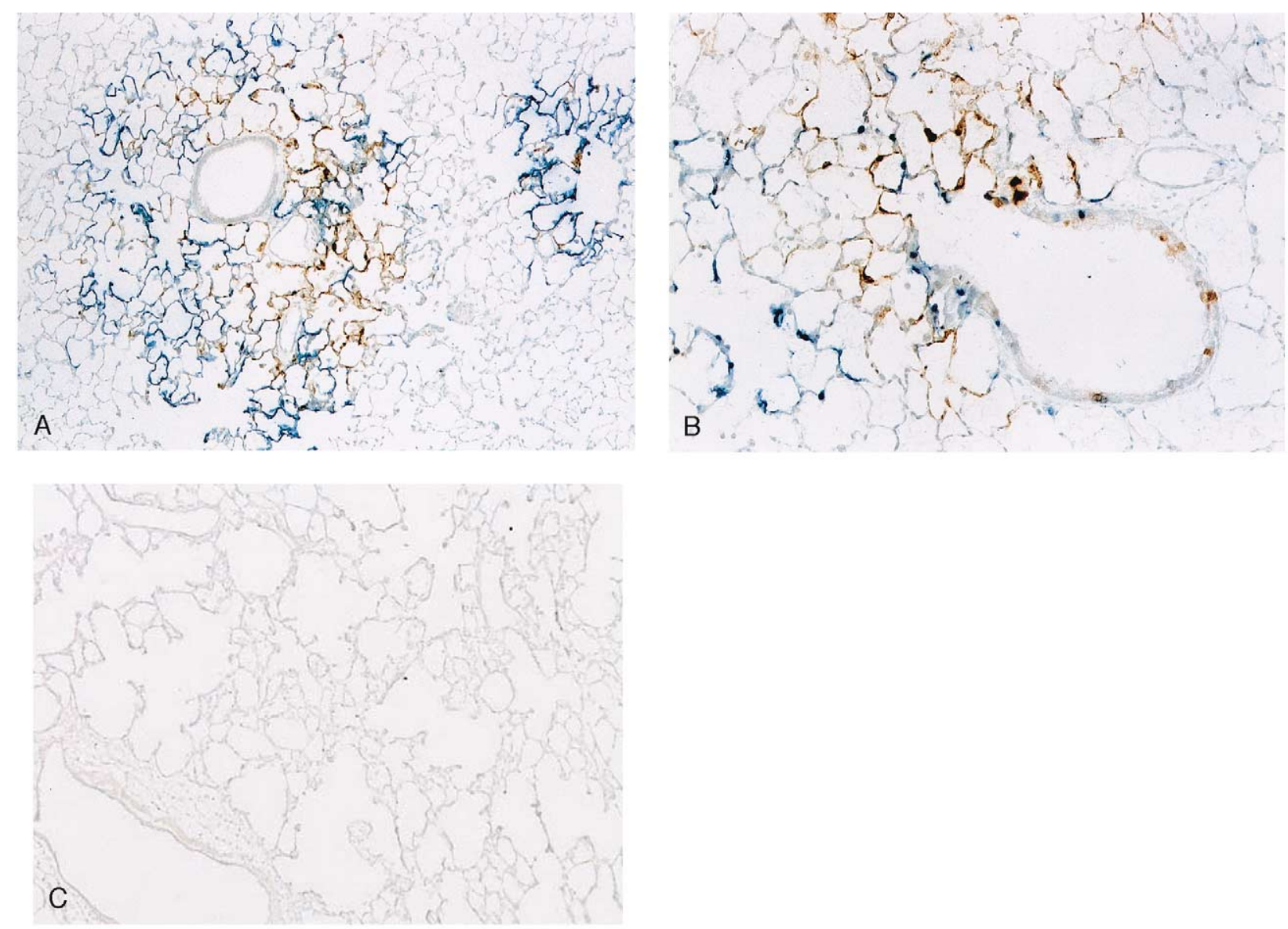

Figure 1. Immunohistochemistry for $\beta$-gal (b/ue) and sTNF-RI-Ig (brown) gene expression in rat lungs. Strong positive staining was observed in airway epithelial cells in cotransfected lungs. $(A$, original magnification, $100 \times$; $B$, original magnification $400 \times$.) The nontransfected control specimen is shown in $C$ at $100 \times$ magnification.

protein), peaked at day $7(126.0 \pm 19.1 \mathrm{ng} / \mathrm{mg}$ total protein), and returned to baseline by day $14(0.01 \pm 0 \mathrm{ng} / \mathrm{mg}$ total protein). The sTNF-RI-Ig protein expression in the $\beta$-gal group was undetectable.

The mean peak $\beta$-gal protein expression on days 2 and 7 was not significantly different between the cotransfection and $\beta$-gal groups $(P=.84$; Figure $2, A)$. Importantly, $\beta$-gal expression in the cotransfection group on days 28 and 56 was significantly higher than that seen in the $\beta$-gal group ( $P$ $=.0007$; Figure 2, $B$ ).

Antiadenovirus antibody production in the cotransfection group was significantly higher than that in the $\beta$-gal group $(P<.0001$, Figure 3). Endogenous TNF- $\alpha$ levels in the lungs of the cotransfection group were lower than those in the $\beta$-gal group $(P=.006)$.

Experiment 3: Examine the effects of STNF-RI-Ig and $\beta$-gal gene cotransfection on $\beta$-gal gene expression after their repeated administration

Repeated cotransfection of sTNF-RI-Ig and $\beta$-gal did not increase $\beta$-gal protein expression in the lung. However, antiadenovirus antibody production was increased on days 9 and 16 in both the cotransfection and $\beta$-gal groups. Furthermore, antiadenovirus titers were significantly higher in the cotransfection group than in the $\beta$-gal group on day $9(P=$ .0025). The endogenous TNF- $\alpha$ level in the lung on days 9 and 16 was not significantly different between the 2 groups $(P=.73)$.

\section{Discussion}

Adenovirus is an important gene therapy vector, but a short duration of expression and the inability to perform repeated administration remain important limitations. Another limitation is that if adenoviruses are delivered in vivo, they infect all tissues, including the germ line, and thus could affect subsequent generations. A further problem is that the current generation of adenoviral vectors are immunogenic, which reduces the duration of gene expression and makes repeated administration of the same vector impossible. ${ }^{16,21}$ Our aim was to investigate whether cotransfection could prolong gene expression and facilitate repeat vector admin- 
ஜ AdCMVLacZ

AdCMVLacZ+AdsTNF-RI-Ig

NS

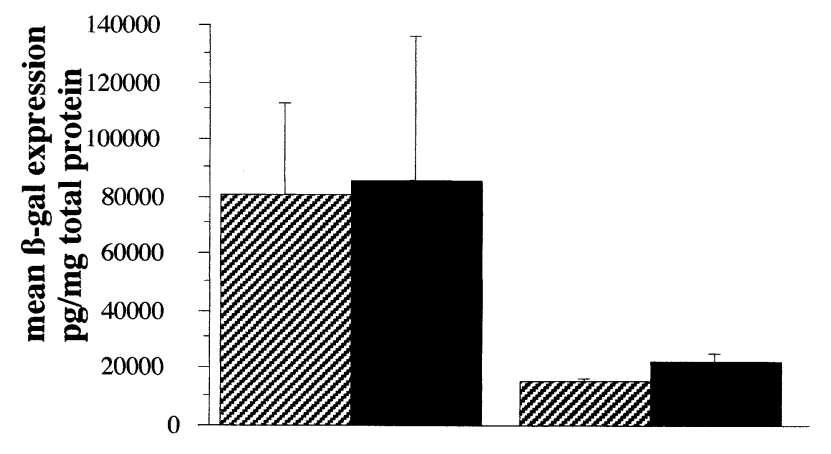

A

Day 2

Day 7

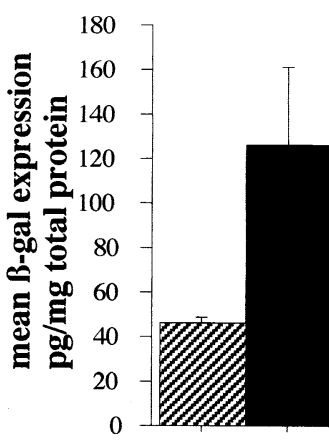

Day 14
Z AdCMVLacZ

AdCMVLacZ+AdsTNF-RI-Ig

B

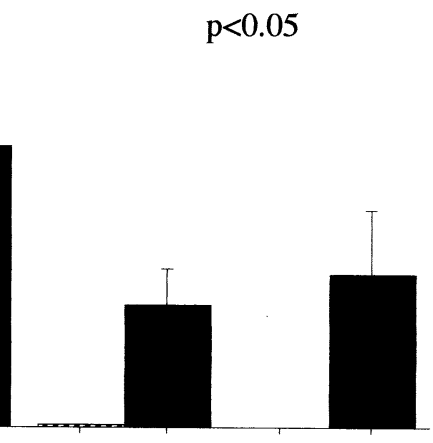

Day 28

Day 56

Figure 2. Mean $\beta$-gal protein expression on days 2 and 7 was not significantly different between the cotransfection (sTNF-RI-Ig and $\beta$-gal) and $\beta$-gal groups. In the $\beta$-gal group $\beta$-gal protein expression was evident on day 2 , decreased at day 14 , and undetectable on day 56. $\beta$-Gal expression in the cotransfection group was prolonged and significantly higher for days 14 to 56 versus that in the $\beta$-gal group.

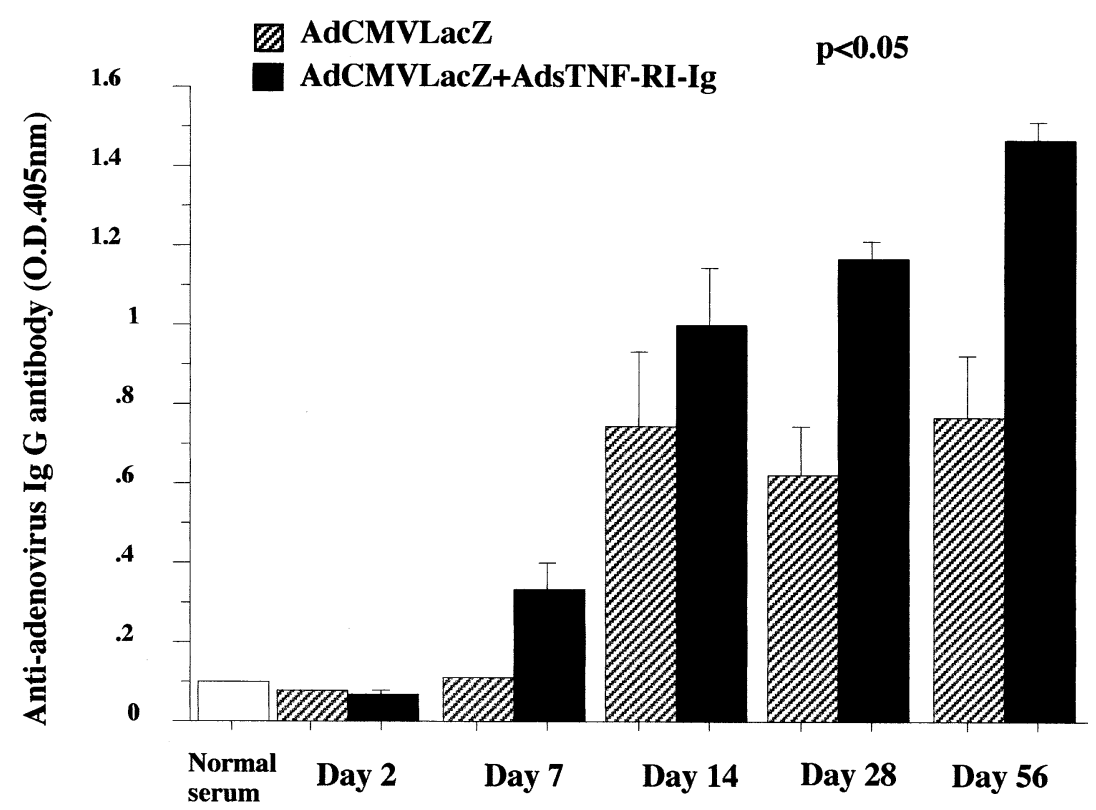

Figure 3. Antiadenovirus antibody production in the cotransfection group was significantly higher than that in the $\beta$-gal group.

istration. In this study we demonstrated that sTNF-RI-Ig and $\beta$-gal cotransfection was feasible and prolongs the duration of $\beta$-gal gene expression. However, repeated sTNF-RI-Ig and $\beta$-gal cotransfection did not have any effect on increasing $\beta$-gal expression.

A principal physiologic function of TNF- $\alpha$ is to stimulate the recruitment of neutrophils and monocytes to sites of infection and to activate these cells to eradicate microbes. In inflammation TNF- $\alpha$ is produced in large amounts and causes systemic clinical and pathologic abnormalities. The effectiveness of TNF- $\alpha$ antagonists, such as STNF-RI-Ig, in ameliorating inflammation of the lung has been demonstrated in acute lung injury. ${ }^{17}$ However, mechanisms of prolonging expression with TNF- $\alpha$ antagonists are less well understood. 
Acute lung injury is characterized by increased proinflammatory cytokine levels and massive neutrophil accumulation in the lung. TNF- $\alpha$ is one of the primary factors driving the early inflammatory response. TNF- $\alpha$ signaling through both the p55 and p75 receptors plays an important role in the clearance of adenoviral vectors and the magnitude of the humoral immune response. ${ }^{22}$ TNF- $\alpha$ also leads to the elimination of adenovirus-infected cells, and sTNFRI-Ig is capable of inhibiting these proinflammatory effects. ${ }^{16,21,23}$ In the present study sTNF-RI-Ig and $\beta$-gal cotransfection prolongs $\beta$-gal expression. This prolonged expression might be caused by the anti-inflammatory effects of sTNF-RI-Ig because it likely inhibits the destruction of infected cells and the subsequent loss of gene expression. This anti-inflammatory effect is similar to that seen in previous studies using TNF- $\alpha$ binding protein with and without adenoviral constructs. ${ }^{12-17}$

However, the expression of $\beta$-gal on days 14 to 56 in the cotransfected group was higher than that in the $\beta$-gal group, but it was substantially lower than the expression on days 2 and 7. The amount of expression after day 14, even though statistically significant, might not be clinically significant or applicable. We need to conduct further studies to investigate how we can achieve prolonged and significant expression for clinical application.

In addition, antiadenovirus antibody production was significantly increased in the cotransfection group. This could be secondary to the fact that the animals in the cotransfection group received a total of $2 \times 10^{9}$ pfu of adenovirus versus only $1 \times 10^{9} \mathrm{pfu}$ in the $\beta$-gal group or that the presence of 2 different adenoviral constructs induces an amplified immune response than that seen when only one adenoviral construct is used. This result suggests that the advantage of cotransfection is the ability to prolong gene expression, but its disadvantage is that the antiadenovirus antibody production is increased, limiting the ability to perform successful repeated vector administration. Hence the antiadenovirus antibody production might be less important in determining the duration of expression than other factors, such as TNF- $\alpha$. On the other hand, Suga and associates $^{24}$ have shown that inhibition of interferon $\gamma$, not TNF- $\alpha$, and antiadenovirus antibody production are related to rejection of adenoviral vectors. Therefore, we need further studies to evaluate which effects are the most important. One way to accomplish this is to augment our experimental design and compare $\beta$-gal expression and antibody production between groups receiving $1 \times 10^{9}$ pfu of adenovirus encoding $\beta$-gal and $1 \times 10^{9}$ pfu of adenovirus encoding sTNF-RI-Ig and groups receiving $1 \times 10^{9}$ pfu of adenovirus encoding $\beta$-gal and $1 \times 10^{9}$ pfu of adenovirus encoding a nontranscribed control gene. In this fashion the effect of sTNF-RI-Ig presence can be determined, and the role of increased viral load can be eliminated.
sTNF-RI-Ig and $\beta$-gal cotransfection was ineffective in augmenting $\beta$-gal expression after their repeated cotransfection. Kolb and associates ${ }^{25}$ showed that the use of topical corticosteroids improved gene expression after repeated injection of adenovirus vectors but did not prevent production of neutralizing antiviral antibodies. We hypothesized that sTNF-RI-Ig would reduce immunogenic responses and make repeated cotransfection possible. However, cotransfection increases the quantity of adenovirus transfected and augments the formation of antibodies to the adenovirus vector. Unfortunately, these antiadenovirus antibodies might limit the success of repeated administration. We also speculate that the low expression might be secondary to the fact that inhibition of the initial nonspecific inflammatory component of the immune response to adenovirus does not necessarily inhibit the development of T or B cell-specific antiadenovirus response, which would lead to low expression. Therefore, preventing the production of antiadenovirus antibodies might be as important as reducing immunogenic responses in allowing successful repeated vector administration.

Currently, gene therapy with adenovirus vectors enlists the synthetic machinery of the patient's cells to produce a therapeutic agent. ${ }^{21}$ In the clinical setting some patients receive several drugs to modulate concurrent biochemical pathways of disease. In experimental septic shock models antagonists of TNF- $\alpha$ can prevent mortality, but clinical trials with anti-TNF- $\alpha$ antibodies or with soluble TNF- $\alpha$ receptors have not shown any benefit in patients with sepsis. This might be because cytokines other than TNF- $\alpha$ elicit similar responses. ${ }^{26,27}$ Therefore, cotransfection might be required to regulate concurrent pathways in clinical gene therapy.

In conclusion, adenovirus encoding soluble TNF- $\alpha$ receptor Ig and $\beta$-gal cotransfection prolonged the gene expression of $\beta$-gal but did not augment its expression after repeat cotransfection. These results suggest that TNF- $\alpha$ is the one of the most important factors to regulate the duration of gene expression. On the other hand, cotransfection increased antiadenovirus antibodies, which might be the reason repeated administration was ineffective.

We thank Dr Paul D. Robbins (Department of Molecular Genetics and Biochemistry and Orthopedic Surgery, University of Pittsburgh School of Medicine, Pittsburgh, Pa) for kindly providing adenovirus encoding TNF-RI-Ig. We also thank Kathleen Grapperhaus for technical assistance and Mary Ann Kelly and Dawn Schuessler for secretarial support. Statistical advice was obtained from Richard B. Schuessler, PhD.

\section{References}

1. Marcel T, Grausz JD. The TMC worldwide gene therapy enrollment report, end 1996. Hum Gene Ther. 1997;8:775-800.

2. Crystal RG. Transfer of genes to humans: early lessons and obstacles to success. Science. 1995;270:404-10. 
3. Swisher SG, Roth JA. p53 gene therapy for lung cancer. Curr Oncol Rep. 2002;4(4):334-40.

4. Suda T, Mora BN, D'Ovidio F, et al. In vivo adenovirus-mediated endothelial nitric oxide synthase gene transfer ameliorates lung allograft ischemia-reperfusion injury. J Thorac Cardiovasc Surg. 2000; 119:297-304.

5. Yano M, Mora BN, Ritter JM, et al. Ex vivo transfection of transforming growth factor $\beta 1$ gene to pulmonary artery segments in lung grafts. J Thorac Cardiovasc Surg. 1999;117:705-13.

6. D'Ovidio F, Yano M, Ritter JH, Mohanakumar T, Patterson GA. Endobronchial transfection of naked TGF-beta1 cDNA attenuates acute lung rejection. Ann Thorac Surg. 1999;68:1008-13.

7. Trapnell BC, Gorziglia M. Gene therapy using adenoviral vectors. Curr Opin Biotechnol. 1994;5:617-25.

8. Yang Y, Nunes FA, Berencsi K, Furth EE, Gonczol E, Wilson JM. Cellular immunity to viral antigens limits E1-deleted adenoviruses for gene therapy. Proc Natl Acad Sci U S A. 1994;88:1172-6.

9. Kanaan SA, Kozower BD, Cassivi SD, Patterson GA. Gene therapy for lung transplantation. In: Albeda SM, editor. Gene therapy in lung disease. New York: Marcel Dekker; 2002. p. 457-73.

10. Cassivi SD, Liu M, Boehler A, et al. Transplant immunosuppression increases and prolongs transgene expression following adenoviralmediated transfection of rat lungs. J Heart Lung Transplant. 2000; 19(10):984-94.

11. Cassivi SD, Liu M, Boehler A, et al. Transgene expression after adenovirus-mediated retransfection of rat lungs is increased and prolonged by transplant immunosuppression. J Thorac Cardiovasc Surg. 1999;117(1):1-7.

12. Williams RO, Ghrayeb J, Feldmann M, Maini RN. Successful therapy of collagen-induced arthritis with TNF receptor-IgG fusion protein and combination with anti-CD4. Immunology. 1995;84(3):433-9.

13. Moreland LW, Baumgartner SW, Schiff $\mathrm{MH}$, et al. Treatment of rheumatoid arthritis with a recombinant human tumor necrosis factor receptor (p75)-Fc fusion protein. $N$ Engl J Med. 1997;337(3):141-7.

14. Le CH, Nicolson AG, Morales A, Sewell KL. Suppression of collageninduced arthritis through adenovirus-mediated transfer of a modified tumor necrosis factor alpha receptor gene. Arthritis Rheum. 1997; 40(9):1662-9.

15. Kim KN, Watanabe S, Ma Y, Thornton S, Giannini EH, Hirsch R. Viral IL-10 and soluble TNF receptor act synergistically to inhibit collagen-induced arthritis following adenovirus-mediated gene transfer. J Immunol. 2000;164:1576-81.
16. Ghivizzani SC, Lechman ER, Kang R, et al. Direct adenovirus-mediated gene transfer of interleukin 1 and tumor necrosis factor $\alpha$ soluble receptors to rabbit knees with experimental arthritis has local and distal anti-arthritic effects. Proc Natl Acad Sci U S A. 1998;95:4613-8.

17. Zhang H, Zhou T, Yang P, Edwards CK III, Curiel DT, Mountz JD. Inhibition of tumor necrosis factor $\alpha$ decreases inflammation and prolongs adenovirus gene expression in lung and liver. Hum Gene Ther. 1998;9:1875-84.

18. Daddi N, Suda T, D'Ovidio F, et al. Recipient intramuscular cotransfection of naked plasmid TGF $\beta 1$ and IL-10 ameliorates lung graft ischemia-reperfusion injury. J Thorac Cardiovasc Surg. 2002;124: 259-69.

19. Elkon KB, Liu CC, Gall JG, et al. Tumor necrosis factor $\alpha$ plays a central role in immune-mediated clearance of adenoviral vectors. Proc Natl Acad Sci U S A. 1997;94:9814-9.

20. Gall J, Kass-Eisler A, Leinwand L, Falck-Pedersen E. Adenovirus type 5 and 7 capsid chimera: fiber replacement alters receptor tropism without affecting primary immune neutralization epitopes. $J$ Virol. 1996;70:2116-23.

21. Blau HM, Springer ML. Gene therapy-a novel form of drug delivery. N Engl J Med. 1995;2:1204-7.

22. Minter RM, Rectenwald JE, Fukuzuka K, et al. TNF $\alpha$ receptor signaling and IL-10 gene therapy regulate the innate and humoral immune responses to recombinant adenovirus in the lung. J Immunol. 2000; 164(1):443-51.

23. Abraham E, Coulson WF, Schwartz MD, Allbee J. Effects of therapy with soluble tumor necrosis factor receptor fusion protein on pulmonary cytokine expression and lung injury following hemorrhage and resuscitation. Clin Exp Immunol. 1994;98:29-34.

24. Suga M, Gladdy R, Xing Z, Keshavjee SH, Liu M. Transplant immunosuppression enhances efficiency of adenoviral-mediated gene retransfection: inhibition of interferon-gamma and immunoglobulin G. Ann Thorac Surg. 2002;73:1092-7.

25. Kolb M, Inman M, Margetts PJ, Galt T, Gauldie J. Budesonide enhances repeated gene transfer and expression in the lung with adenoviral vectors. Am J Respir Crit Care Med. 2001;164(5):866-72.

26. Beutler B. TNF, immunity and inflammatory disease: lessons of the past decade. J Investig Med. 1995;43:227-35.

27. Kolls JK, Lei D, Nelson S, Summer WR, Greenberg S, Beutler B. Adenovirus-mediated blockade of tumor necrosis factor in mice protects against endotoxic shock yet impairs pulmonary host defense. J Infect Dis. 1995;171(3):570-5. 